\title{
Training Hospital Readiness in Speech-Language Pathology Students through Simulation
}

Anna Miles

University of Auckland, a.miles@auckland.ac.nz

Selena Donaldson

University of Auckland, s.donaldson@auckland.ac.nz

Philippa Friary

University of Auckland, pm.williams@auckland.ac.nz

Follow this and additional works at: https://nsuworks.nova.edu/ijahsp

Part of the Educational Methods Commons, Medical Education Commons, and the Speech Pathology and Audiology Commons

\section{Recommended Citation}

Miles A, Donaldson S, Friary P. Training Hospital Readiness in Speech-Language Pathology Students through Simulation. The Internet Journal of Allied Health Sciences and Practice. 2015 Oct 10;13(4), Article 8.

This Manuscript is brought to you for free and open access by the College of Health Care Sciences at NSUWorks. It has been accepted for inclusion in Internet Journal of Allied Health Sciences and Practice by an authorized editor of NSUWorks. For more information, please contact nsuworks@nova.edu. 


\title{
Training Hospital Readiness in Speech-Language Pathology Students through Simulation
}

\begin{abstract}
Simulated learning environments allow students to develop technical and clinical decision-making skills in a safe and realistic setting. The aim of this study was to evaluate speech-language pathology students' perception of hospital readiness following a one-day simulation-based training day on swallowing management. Nineteen students attended the training day. Training included part-task skill learning and immersive simulated scenarios. Students were asked to complete course evaluation forms and participated in focus groups immediately after the day. Seven students participated in a further focus group after a five-week hospital placement within a month of the training day. Four students participated in a focus group after a five-week hospital placement three months after the training day. The training day was positively accepted by all students. Analyses revealed three global themes: (1) preparation for hospital environment, (2) speech-language pathology skills, and (3) impact of simulated learning environments. Students directly attributed increased confidence in working in the hospital environment and increased clinical competency to the training day. These themes continued up to three months post training. Simulated learning environments may have long lasting benefits in developing hospital readiness in speech-language pathology students.
\end{abstract}

\section{Author Bio(s)}

- Anna Miles, PhD, is a full-time faculty member in Speech Science, Psychology at the University of Auckland. Dr. Miles is a researcher, lecturer, and clinician in the area of swallowing and swallowing disorders. She is also the New Zealand Speech-language Therapists' Association Clinical Expert in Adult Dysphagia.

- Selena Donaldson, MSc, is a Professional Teaching Fellow at the University of Auckland, and Associate Director of Allied Health at Counties Manukau Health. She is also an Expert Advisor to New Zealand Speech Language Therapy Association (NZSTA) for acquired brain injury.

- Philippa Friary, BSc (Hons), is the Clinical Director of the Speech Sciences programme at The University of Auckland, New Zealand. Philippa has a keen interest in interprofessional education and exploring innovative ways to enhance interprofessional collaboration. Philippa is also the President of the New Zealand Speech-language Therapists' Association.

\section{Acknowledgements}

Thank you to the staff at The University of Auckland Simulation Centre for Patient Safety, Tamaki Campus for their expertise: Jane Torrie, Abbey Gundesen and Brenda Knowles. The authors would like to specifically acknowledge the support of Jane Torrie in both training day planning and manuscript preparation. Thank you to Bianca Gordon, Emma Necus and Malcolm Borrie for their contribution to the planning and facilitation of the training day. 


\title{
TIAHSP \\ The Internet Joưtnal of Allied Health Sciences and Practice
}

Dedicated to allied health professional practice and education

Vol. 13 No. 4 ISSN 1540-580X

\section{Training Hospital Readiness in Speech-Language Pathology Students through Simulation}

\author{
Anna Miles, $\mathrm{PhD}^{1}$ \\ Selena Donaldson, $\mathrm{MSc}^{2}$ \\ Philippa Friary, BSc (Hons) 3
}

1. Lecturer, Speech Science, The University of Auckland, Auckland, New Zealand

2. Professional Teaching Fellow, Speech Science, The University of Auckland, Auckland, New Zealand

3. Clinical Director, Speech Science, The University of Auckland, Auckland, New Zealand

New Zealand

\begin{abstract}
Simulated learning environments allow students to develop technical and clinical decision-making skills in a safe and realistic setting. The aim of this study was to evaluate speech-language pathology students' perception of hospital readiness following a one-day simulation-based training day on swallowing management. Nineteen students attended the training day. Training included part-task skill learning and immersive simulated scenarios. Students were asked to complete course evaluation forms and participated in focus groups immediately after the day. Seven students participated in a further focus group after a five-week hospital placement within a month of the training day. Four students participated in a focus group after a five-week hospital placement three months after the training day. The training day was positively accepted by all students. Analyses revealed three global themes: (1) preparation for hospital environment, (2) speech-language pathology skills, and (3) impact of simulated learning environments. Students directly attributed increased confidence in working in the hospital environment and increased clinical competency to the training day. These themes continued up to three months post training. Simulated learning environments may have long lasting benefits in developing hospital readiness in speech-language pathology students.
\end{abstract}

\section{INTRODUCTION}

Speech-language pathologists (SLPs) work in a range of settings: home health, schools, clinics and hospitals. One of the roles of an SLP is working with people with feeding and swallowing difficulties (dysphagia) in the hospital setting. ${ }^{1}$ It is within an SLPs' scope of practice to perform clinical and instrumental swallowing evaluations, make decisions about feeding and treatment, provide treatment, educate, and counsel and advocate for people with feeding and swallowing difficulties. ${ }^{2}$

Preparing students for clinical practice is complex. Like other settings, the hospital environment tests students' emerging skills. The acute medical setting can be stressful and feeling psychologically unprepared leads to increased anxiety.3.4 When 258 clinical educators across Queensland, Australia were surveyed about indicators of readiness for hospital placements in allied health students, the researchers identified six themes: willingness, professionalism, personal attributes, communication and interaction, knowledge and understanding, and skills. ${ }^{5}$ Interestingly, clinical educators prioritized willingness and personal attributes over knowledge. Students' ability to "manage their stress level,", "willingness to work as a team," and "stray from their

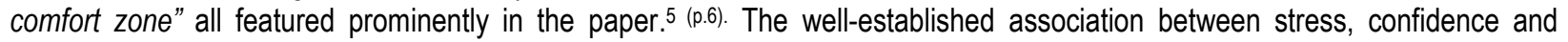
students' performance implies that building confidence and relieving student stress may improve clinical performance..$^{6-8}$ Early clinical experiences and early familiarization training are popular practices to build confidence and reduce student tension. ${ }^{9}$

One approach for preparing students for clinical situations is simulation. Simulation is the "immersion of a trainee in a realistic situation (scenario) created within a physical space (simulator) that replicates the real environment with fidelity (degree of similarity) sufficient to achieve suspension of disbelief on the part of the trainee."10 (p. 379) Simulated learning environments (SLEs)

(C) The Internet Journal of Allied Health Sciences and Practice, 2015 
are now commonplace in medical and nursing teaching..$^{10}$ In medical simulation, this typically entails students working through clinical scenarios in mock hospital wards with manikins and /or actors. ${ }^{10}$ SLEs allow skills to be learnt without risk to the patient in a realistic clinical setting and well received by trainees. ${ }^{9-12-14}$

SLEs are becoming more common in allied health teaching. A recent survey of the Association of Allied Health Professions (ASAHP) found $40 \%$ of institutions were using some form of virtual learning environment. ${ }^{15}$ Across medical and allied health professions, there is evidence that SLEs improve confidence and reduce anxiety, as well as improve professional communication skills, technical skills, teamwork, and critical thinking skills. $9,11,14,16-22$

There is less evidence of the benefits of SLE in speech-language pathology. Undergraduate and graduate SLP students responded positively to a standardized patient experience where actors played the role of a parent with a child with communication difficulties in a mock clinic setting. ${ }^{14}$ Students were more confident and less anxious after their 12 allocated sessions. There was a positive correlation between increased confidence and decreased anxiety. ${ }^{14}$ SLPs have also shown improvements in technical skills: transnasal endoscopy and tracheostomy management through the use of high-fidelity simulation training (using advanced patient simulators (manikins that can display physiological symptoms such as breath and speak)..$^{13,23}$

Simulation has been proposed as an intermediate stage of learning, placed between theoretical study and clinical practicum . ${ }^{24}$ Simulation training builds on experiential learning theory, allowing the student to interact within the learning environment and reflect on performance safely. ${ }^{24}$ Traditionally, medical professionals were expected to transfer theoretical knowledge into competent practice automatically following a short period of observation - "see one, do one, teach one." 24 This "inevitably leads to considerable anxiety and does not promote high-level reflective, clinical decision-making."25,26 It appears these negative responses to early clinical exposure are offset when students are engaged in SLEs. Physiotherapy students show equivalent clinical competencies from SLE than traditional clinical practicum. ${ }^{27}$ Medical students performed twice as well with half the training when cardiology examination skills were taught using a simulator rather than solely through ward observation. ${ }^{28}$ Superior skills in cardiac resuscitation were found in medical students who received simulation-based training compared with those who had three months of clinical experience..$^{29}$

SLEs actively encourage students to engage in reflective practice and to incorporate previous knowledge into clinical reasoning. ${ }^{24}$ It is possible that this may lead to increased confidence and willingness in SLPs to try out skills while on hospital placement. SLEs may support SLP students to become familiarized with the hospital environment and gain the technical skills required. In turn, students may, then, arrive on placement with the confidence and personal attributes required for successful learning. In comparison to medical students, little has been published on the impact of simulation on SLP students. Most importantly, while immediate effect of SLEs on knowledge and skills is well established, little has been documented about the long-term effect of SLEs. The aim of this study was to evaluate students' perception of hospital readiness following one day of simulation-based training on swallowing management. The following research questions were investigated: Do SLP students accept simulated learning positively? Do SLP students perceive benefits to simulated learning for increasing their confidence and knowledge and preparing them for the hospital environment? Do students perceive benefits to simulated learning when there is a delay of three months before they are able to apply their learning?

\section{METHODS}

\section{Participants}

Nineteen students enrolled in a speech-language therapy program participated in a one-day training as part of a dysphagia (swallowing disorders) course. All students were in their first year of the two-year program with no prior hospital experience. They had all completed one semester of pediatric and adult weekly outpatient speech and language clinic experience. The training day was completed mid-way through the students' eight-week theoretical dysphagia course. This study received appropriate regional ethics approval from University of Auckland Human Participants Ethics Committee (10126) Prior to the training, all students provided written consent to complete a written questionnaire and attend focus groups, consistent with the ethics application.

\section{The Training Day}

The overarching objective was to prepare students for working with hospitalized patients with swallowing difficulties across the lifespan. The training day comprised of three components: part-task skill learning, orientation to the ward environment, and simulated scenarios.

Three experienced speech-language therapist clinical educators and three experienced simulation center technicians conducted the training. All three clinical educators were experienced in simulation training and were known to the students. The two

(c) The Internet Journal of Allied Health Sciences and Practice, 2015 
simulation technicians are experienced nurses now specializing in simulation training. The third staff member, the director of simulation-based training center, is an experienced anesthetist.

\section{Part-Task Skill Training}

The part-task skill learning involved students working through a set of seven supervised skill stations with an emphasis on repeating each task as many times as possible within a 15-minute time frame (table 1). Part-task skills were chosen as key clinical skills required by SLPs in conducting a swallowing assessment. Students were provided with written instructions at each station and were encouraged to become familiar with equipment. Clinical educators were present at each station to supervise competence and answer questions.

Table 1. Part-Task Skill Stations

\begin{tabular}{|l|l|}
\hline \multicolumn{1}{|c|}{ Skill Stations } \\
\hline 1 & Introducing the role of the SLP in swallowing to a patient and their family across a variety of clinical etiologies \\
\hline 2 & Identifying salient information from clinical notes \\
\hline 3 & Identifying normal versus abnormal vital signs from an observation sheet across the lifespan \\
\hline 4 & Cranial nerve exam in a baby \\
\hline 5 & Cranial nerve exam- in a child/adult \\
\hline 7 & Cervical auscultation \\
\hline
\end{tabular}

\section{Orientation to the Ward Environment}

The students were then orientated to the simulated ward environments: a pediatric ward, an adult high dependency unit and a general medical adult ward. These wards are part of a specialized university-based Simulation Centre for Patient Safety. Students received instruction in infection control, emergency procedures, lifting a patient bed, and reading a patient monitor from the simulation technicians. They then completed a "treasure hunt" where they were asked to locate a list of commonly used equipment based on the key clinical SLP skills taught in the part-task skill training. Equipment included oxygen masks, gloves, and tongue depressors. This is a common simulation procedure as it ensures students are familiarized with the rooms and equipment location prior to entering the simulated scenarios. ${ }^{24}$

\section{Simulated Scenarios}

Finally, students worked through three simulated scenarios (table 2). Scenarios were developed by the six members of the training team who all had extensive experience in scenario development. The students were split into two groups of six and one group of seven, each group rotating through all three scenarios by the end of the day. Confederates, played by members of the training team, were present in the simulation room playing the parts of key members of the hospital team. ${ }^{1}$ One additional speech-language therapist was employed to play the part of a mother in the Scenario 2 and one gentleman with Parkinson's disease volunteered to play the standardized patient in Scenario 3. ${ }^{1}$ Both were provided with one-hour of training in simulation education and provided with scenario plans and scripts. Prior to each scenario, each group of six students discussed patient case history and made plans for the assessment. Students worked in pairs within the scenario with their peers observing from an observation room.

A "pause and discuss" approach was encouraged where students could pause the scenario at any time in order to discuss clinical decisions with their peers. ${ }^{30}$ Scenarios were split into phases at natural pauses in each assessment, for example, after the case history and prior to a cranial nerve exam. The scenario was "paused" by the facilitator at the end of each phase. This allowed all students to take a turn in the simulation room and allowed time for debriefing. One educator watched each scenario from the observation room and facilitated these debriefing periods. Debriefing and reflection was deemed a critical component of the scenarios and skilled facilitators ensured that discussions were constructive, supportive and focussed. ${ }^{30}$ 
Table 2. Simulated Scenarios

\begin{tabular}{|c|c|c|c|c|}
\hline Scenario & $\begin{array}{l}\text { Patient Requiring } \\
\text { Swallowing } \\
\text { Assessment }\end{array}$ & Simulator & Confederates & Learning Objectives \\
\hline Scenario 1 & $\begin{array}{l}\text { Semiconscious } \\
\text { unstable patient } \\
\text { within 24-hours } \\
\text { after stroke } \\
\text { Stroke Ward } \\
\text { setting }\end{array}$ & $\begin{array}{l}\text { Manikin (Laerdal } \\
\text { SimMan® 3G) }\end{array}$ & $\begin{array}{l}\text { Nurse } \\
\text { Senior SLP }\end{array}$ & $\begin{array}{l}\text { - } \quad \text { introducing your role to the patient } \\
\text { - } \quad \text { reading clinical notes for general } \\
\text { - } \text { medical status } \\
\text { - } \quad \text { understanding vital signs } \\
\text { regaring general observations } \\
\text { (LOC) } \\
\text { - } \text { making general observations } \\
\text { regarding respiratory status } \\
\text { - observing spontaneous } \\
\text { - } \quad \text { attemallowing (in lying/ in sitting) } \\
\text { - } \quad \text { making decisions about } \\
\text { termination versus continuation of } \\
\text { a swallowing assessment } \\
\text { reporting findings to a nurse }\end{array}$ \\
\hline Scenario 2 & $\begin{array}{l}\text { One-month old } \\
\text { infant following } \\
\text { congenital heart } \\
\text { surgery } \\
\text { Pediatric Cardiac } \\
\text { Ward setting }\end{array}$ & $\begin{array}{l}\text { Baby manikin } \\
\text { (BabySIM®, CAE } \\
\text { Healthcare) }\end{array}$ & $\begin{array}{l}\text { Mother } \\
\text { Doctor } \\
\text { Nurse }\end{array}$ & 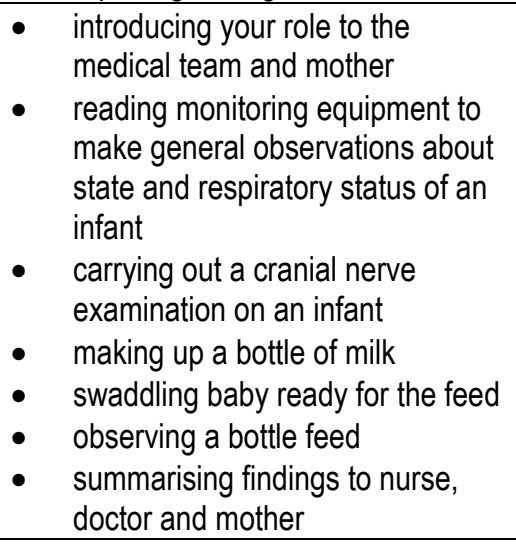 \\
\hline Scenario 3 & $\begin{array}{l}\text { Adult with } \\
\text { Parkinson's } \\
\text { disease } \\
\text { hospitalized with a } \\
\text { chest infection } \\
\text { General Medical } \\
\text { Ward setting }\end{array}$ & $\begin{array}{l}\text { Standardized } \\
\text { patient }\end{array}$ & Nurse & $\begin{array}{l}\text { - } \quad \text { introducing self and role to patient } \\
\text { and nurse } \\
\text { - } \quad \text { understanding clinical notes and } \\
\text { vital signs } \\
\text { - } \quad \text { making general observations } \\
\text { about LOC and respiratory status } \\
\text { - completing an appropriate case } \\
\text { history } \\
\text { - } \quad \text { applying a systematic approach to } \\
\text { cranial nerve examination } \\
\text { - applying a systematic approach to } \\
\text { oral trials observations } \\
\text { - discussing findings confidently } \\
\text { with patient and nurse }\end{array}$ \\
\hline
\end{tabular}

\section{Mixed Methods Design}

\section{Questionnaire}

Immediately prior to and immediately after training, students were asked to complete a questionnaire comprised of six questions regarding confidence, knowledge and perception of preparedness for working in a hospital environment (table 3) and one question regarding their perception of the suitability of simulation in developing skills in the hospital setting. Each question 
required the student to indicate their response on a 10-point Likert scale ranging from novice (1), through intermediate (5) to entry level (10). The questionnaire was developed by all six members of the training team. After the training day, there was an opportunity to include written feedback on the form: "Please provide any thoughts regarding the training day."

\section{Focus Groups}

Focus groups were employed as a further method of gaining the students' perspectives of the training and its efficacy. Many of the strengths of focus group methodology align favorably with group work learning - a common teaching method throughout the Masters of Speech Language Therapy Practice. ${ }^{32,33}$ As this was a peer group, it was felt that there would be rich, naturally occurring data in their group processes. ${ }^{34}$ It was also reasoned that focus groups would help alleviate student reluctance to openly discuss perceived drawbacks of negative aspects of the study day, which might occur with an interview format. ${ }^{35}$ Focus groups have been highlighted in the literature as sensitive to cultural variables: empowering participants who may have been culturally more inclined to remain passive in a more hierarchical platform. ${ }^{34}$ This is particular pertinent to this cohort of participants who were multi-cultural (New Zealand European 9, Asian 7, Pacifica 1, Other 2), mixed in age (23 to 38 years) and had similar experience of providing service feedback.

A focus group was conducted with the full cohort immediately after training (Immediate Feedback). Seven students had a fiveweek hospital placement within one month following training. These students participated in another focus group immediately after placement (Early Placement Feedback). Eight students had education-based placements and were not interviewed further. Four students had a five-week hospital placement three months following training and these students participated in a focus group immediately after their placement (Delayed Placement Feedback). Focus groups took place within a quiet academic space at the university. They were facilitated and audio-recorded by either the second or third author and transcribed by the first author. Participants were reassured that their contributions would remain anonymous. The facilitator introduced the session with a brief welcome and acknowledgement of the purpose. A semi-structured approach was employed to elicit the student feedback with the following probes: i) How prepared for the hospital setting do/ did you feel? and ii) What do you feel unprepared for when going on a hospital placement? 35,36 The facilitator continued the focus groups until students indicated they had exhausted their ideas. Saturation typically took approximately 20 minutes.

\section{Data Analysis}

Mean, range and standard deviation (SD) of students' $(n=19)$ ratings on the 10-point Likert scales were calculated and Wilcoxon Signed Ranks Test was used to assess change between pre- and post- training day scores. Thematic analysis was used to identify and interpret patterns across the data. An inductive process was used, in that codes and themes emerged from the transcribed data from the student participants. The researchers sought to expose the students' perceptions of the SLE for readiness to participate in the clinical tasks required of an SLP student, rather than to examine the effects of the various data collection methods used in this study (focus groups versus written feedback from the questionnaires). The raw data, consisting of transcribed quotes and verbatim written feedback from the students at all timeframes, were combined as one document for analysis. Themes were primarily extracted at a semantic level, from the surface or explicit content inherent in the students' quotes. This processed into interpretative analysis as hospital readiness was considered, and as the data exposed underlying views about simulation as a teaching mechanism.

Braun and Clarke's phases of thematic analysis (familiarization, transcription, code generation, theme defining) formed the basis of analysis for the current study, due to its flexibility and accessibility for the novice qualitative researcher. ${ }^{37}$ The data analysis was completed by the first and second authors collaboratively to establish agreement on theme allocation. Both had been involved in aspects of, but not all, focus group discussions and had some insight into the opinions that had been expressed. With years of hospital-based SLP clinical work experience collectively, analysis took place with a solid understanding of the contexts and discussions inherent in the descriptive data.

The second author read all data multiple times to become familiar with the content, before generating the basic themes. All data are represented under one of the basic themes irrespective of whether it was mentioned by one student or multiple students. This was conducted manually and presented to the first author for consideration along with initial suggestions for potential organizing and global themes. These were discussed and if there was a difference of opinion about themes, they were reallocated through discussion and by agreement. The third researcher was available to provide a deciding allocation if resolution was not achieved between the first and second researchers. However, this was not required. Data were color-coded by origin (Immediate Feedback, Early Placement Feedback and Delayed Placement Feedback) to allow researchers to determine if all themes persisted across time. Quotes which exemplified popular themes in a particularly articulate or resonant manner were selected at this stage to guide the researchers' interpretation.

(C) The Internet Journal of Allied Health Sciences and Practice, 2015 


\section{RESULTS}

Students' ratings of the suitability of simulation for developing skills in the hospital setting were relatively high prior to the training day (mean 8 out of possible 10, range 5-9). Ratings were significantly higher immediately after the training day (9 out of possible 10 , range $8-10, p<.01)$. Student evaluations of the training day were positive with $95 \%$ rating "strongly agree" to the content was appropriate and $84 \%$ rating "strongly agree" to the course was realistic. There was a significant increase in students' self-ratings of confidence, preparedness and knowledge after the training day in comparison to before training (table 3 ).

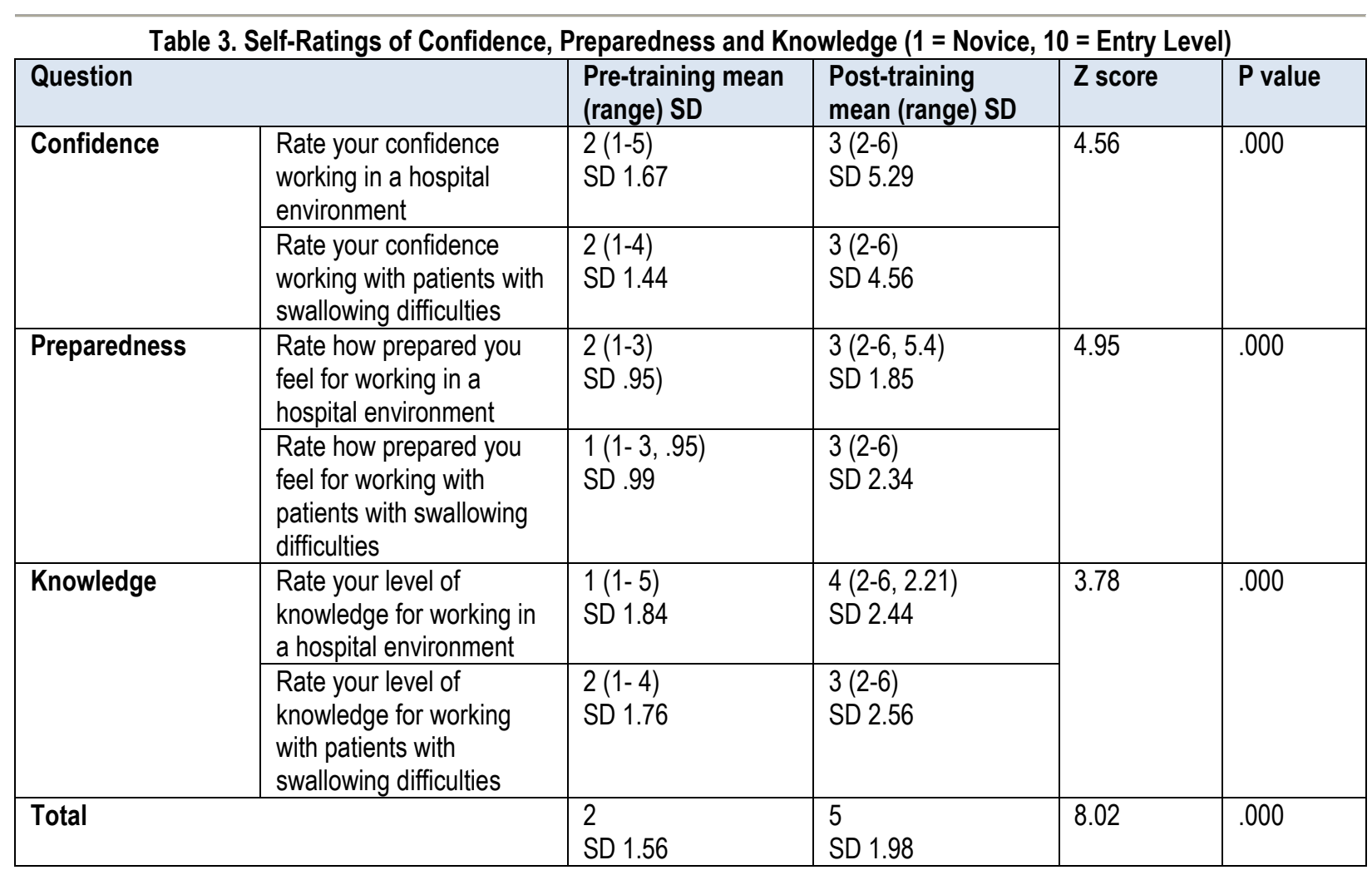

The final global themes that emerged from the data were: (1) preparation for the hospital environment, (2) SLP skills, and (3) [reflections on] simulated learning environment. The organizing and basic themes contributing to these global themes are presented in table 4 in alphabetical order. Data from the three feedback time points were represented across all organizing and basic themes. This paper describes each global theme in turn by examining the organizational themes illustrated with quotes from the students. The basic themes are encapsulated in the quotes selected. 
Table 4. Themes

\begin{tabular}{|c|c|c|}
\hline Global Themes & Organizing Themes & Basic Themes \\
\hline $\begin{array}{l}\text { Preparation for Hospital } \\
\text { Environment }\end{array}$ & $\begin{array}{l}\text { Atmospheric challenges - smells/ } \\
\text { sounds } \\
\text { Comfort } \\
\text { Communication } \\
\text { Familiarisation } \\
\text { Procedures }\end{array}$ & $\begin{array}{l}\text { Bustle } \\
\text { Communication } \\
\text { Coping with distress } \\
\text { Equipment } \\
\text { Family distress } \\
\text { Hygiene } \\
\text { Infection control } \\
\text { MDT working } \\
\text { Moving and handling } \\
\text { Sensory challenges } \\
\text { Where things are kept }\end{array}$ \\
\hline Speech Pathology Skills & $\begin{array}{l}\text { Clinical props } \\
\text { Clinical protocols } \\
\text { Efficiency } \\
\text { Familiarisation } \\
\text { Roles }\end{array}$ & $\begin{array}{l}\text { Anxiety and nervousness } \\
\text { Clinical record-keeping } \\
\text { Communicating findings } \\
\text { Identity } \\
\text { Resources } \\
\text { Self-awareness } \\
\text { Skills-drills } \\
\text { Time-management }\end{array}$ \\
\hline $\begin{array}{l}\text { Impact of Simulated Learning } \\
\text { Environment }\end{array}$ & $\begin{array}{l}\text { Feelings of stress } \\
\text { Group learning } \\
\text { Realism } \\
\text { Safety } \\
\text { Practical learning }\end{array}$ & $\begin{array}{l}\text { Anxiety } \\
\text { Doing no harm } \\
\text { Flashbacks } \\
\text { Making mistakes } \\
\text { Not knowing what you don't know } \\
\text { Reflective practice } \\
\text { Wanting more [of the same learning } \\
\text { mechanisms] }\end{array}$ \\
\hline
\end{tabular}

\section{Global Themes}

\section{Global Theme 1. Preparation for the Hospital Environment}

Five organizing themes emerged capturing feeling familiar and comfortable with the atmospheric and procedural demands of clinical placement in a hospital (table 4). The students felt that being able to communicate appropriately assisted with this, as did feeling familiar with the context and equipment. As one student described, "less shocked and overwhelmed with the hospital atmosphere-more confident going in- have more confidence that what l'm doing is right" and another student recalled, "it was interesting how helpful the little things like how to lift a bed was. How much it actually boosts your confidence." Equipment familiarity was commonly reflected on, "just little things like the cranial nerve and doing the bed-lift made me feel like I knew something." Hand hygiene and infection control procedures was commented on favourably, as students felt familiar from the outset with what was expected of them and explained being able to rise to the strict protocols imposed by their hospital placement. Examples of this included "as soon as you walk in sanitise, after, sanitise, so these were all tips that were very helpful" and "...get off on the wrong foot just because you don't know the tiny little things like the hand hygiene." One student felt better able to cope with the small bedside space posed by ward-based clinical work "where to place yourself, where you should be."

Some limitations of the training day were identified under this theme. Whilst students reported confidence in interacting with the hospital multidisciplinary team, the complexity of communicating with worried family members was perceived as not conveyed in the training. This was felt to be a limitation by one student. Furthermore, whilst individual procedures were practiced, the training day did not prepare students fully for the unique hospital atmosphere. One student recalled, "the bustle and the coming and going to people and beds and wheelchairs and a bed that has been covered over and you are like 'oh my gosh."'

Students used language suggesting that their apprehensive feelings and emotions had been alleviated by participation in simulation prior to their hospital placement. Typical examples included; "ess shocked and overwhelmed," "just getting that shocked feeling over and done with," and "less anxious." 


\section{Global Theme 2. Speech Pathology Skills}

Familiarization was a popular concept, pertaining to the application of speech-language pathology tasks (e.g. cough reflex testing, cranial nerve examination) on clinical placement in a hospital, after the simulation training. Students discussed several aspects of undertaking assessments in the hospital with a clearer sense of: what was expected of them as an SLP, what preparation they had to do before seeing the patient, what equipment they would need, what clinical practice they would be required to undertake with the hospital patient, and the written and verbal communication that was required. Whilst these were not all aspects taught exclusively during the training day, the students discussed feeling that they were more efficient in the novel context of the hospital, which was a specific product of the simulation training.

Exploring and extracting the relevant information from clinical notes prior to seeing the patient was perceived as being optimized by the training day. For example, one student explained, "you only have time to flick rather than sit there and read the whole thing. The training taught me that." The students appeared to understand that they were part of the team with a distinct role, and felt empowered to rise to this challenge, even as a student clinician, "you are more aware and conscious of what is expected of you." The following student acknowledged the overt role that simulation training had in preparing her for conducting clinical work amongst multidisciplinary colleagues, "definitely a chance to use our skills on real patients and doctors." Numerous students described equipment familiarization. They reflected on the demands of managing equipment, their realization that the patient is a unique individual, and their clinical decision-making as student on placement. The following quotes were typical: "[making sure I was] observing closely all the time, vital stats, anything I can note while I'm talking to a patient might be relevant to assessment," "clear instructions and explanations of assessments," "mostly efficiency of assessment - being prepared, knowing what questions to ask." Some students reflected more specifically on the SLP tasks, such as "more competent at the cranial nerve exam and cervical auscultation and cough reflex testing and just putting the three parts together and knowing where to inject the solution for the cough test."

Nevertheless, despite the variety of clinical situations presented in simulation, a student still described feeling unprepared for some aspects of hospital work. One student described the complexity of working with real patients "most of them were overweight or really thin and stuff with thin skin. It made it much more difficult. Different to listening to each other's swallows. I wish l'd had more of that." The same student raised the issue of patients who are not positioned appropriately to undertake a swallowing assessment. "IIn simulation] we did it on each other which was a lot easier than doing it on patients who are lying down and have different body shapes."

\section{Global Theme 3. Impact of Simulated Learning Environment "Safe" Rehearsal Space}

This was a popular theme and one that the students clearly articulated in their reflections. They perceived SLEs as a safe place to rehearse skills for their hospital placement, "great environment to make mistakes." The students acknowledged the novel context of SLEs in comparison to other teaching approaches such as online learning and lecture content, "the difference between having book knowledge and actually applying it. It was like two different worlds. So it was good putting this into practice." The balance between challenge and satisfaction was verbalized by a number of students: "the dropping of the reins, allowing us to make mistakes in a safe environment," and "the stress you feel is real and hopefully exposure to it now will lessen the effects when in the real hospital." Students described abating of fear with the simulated scenarios and repeatedly expressed that they would rather this occurred in the "safety" of the SLE than while on placement.

\section{Learning from Peers}

More than one student reported appreciating the group learning and the discussions that ensued in this context, which complemented the actual simulations, "skills-drills was the most useful. They really had an effect. Going through all the components one by one. Going back over them in groups and getting feedback as well."

Peer learning was positively identified. One student described benefitting from the simulation experiences of their colleagues, "being in the room with the client and being put on the spot with decisions- I like also watching others and seeing what they would do and discussing the rationale for decision making." The students reported on the authenticity of the scenarios. They described the usefulness of this in terms of their learning, "the realistic situations- really stimulating, relevant and helpful to concreting our understanding," and "it felt very real."

\section{Long-Term Learning}

There was longevity evident in the students' recollections of how the simulation had assisted them. There were no differences in global and organising themes across the three time points. The only additional basic theme in the Delayed Placement Feedback focus group was "Flashbacks." Two students described "flashback" as "you walk in and you look at the client for symmetry and

(c) The Internet Journal of Allied Health Sciences and Practice, 2015 
things. So I was trying to get flash backs of what we did and try and use it," and "just little things. Little flash backs even after all these months," Others in the Delayed Placement Feedback focus group described the subconscious process of encountering a situation in the hospital and aspects of the simulation suddenly being recalled, assisting them with their clinical intervention, "I think for me definitely when I was in the moment and I was with the patient then what I learnt came back to me." and "I remembered how it had felt the same in the sim lab- the pressure to do what the nurse says."

\section{DISCUSSION}

Students who participated in this training day perceived that SLE had increased their hospital readiness. The students described increased confidence, skill-acquisition and a greater familiarity with the hospital environment. 13,14,29 Like qualified SLPs, students in the current study listed a number of core clinical skills (e.g. cough reflex testing, cranial nerve examination) that they believed they had acquired during the simulation day. ${ }^{13}$ Students spoke positively about the part-task skill training stations, and it is perhaps this "breaking down of the tasks and building it up again" that supported SLP skill-acquisition. Rodgers described this segmentation of a complex task as an important part of skill development; while the simulated scenarios build on critical thinking skills and skills in managing unexpected circumstances. ${ }^{24}$ This distinction was clearly articulated by the students, "it was nice having the skills broken down in the morning and then being in the room with the patient. Being put on the spot."

Familiarity with general hospital protocols such as hand hygiene and infection control were common basic themes. This was often linked by students to feelings of empowerment "made me feel prepared." The value of knowing something before the clinical placement allowed students not to approach all aspects of work as a "novice." With increased confidence and familiarity with tasks as well as the setting, it is feasible that the SLE facilitated a willingness in students to try new skills and embed new learning. As Chipchase et al reported, students may enter their hospital placements with the skills educators' desire - greater ability to "manage their stress levels"and willingness to "stray from their comfort zone." 5

The feedback from students supports previous findings showing a positive response to simulated learning. ${ }^{14,22,38}$ There was a unanimous positive response to the training day from SLP students, "I learnt so much. I learnt more in one day than on the whole programme so far." In 2013, MacBean et al surveyed the use of simulation in SLPs in Australia. Despite limited use, they found a national willingness and interest in this method of education. ${ }^{39}$ These data support the initiative of the authors to develop a nationally endorsed recommendation for SLE development in Australia and New Zealand. Although clinical skills in managing swallowing difficulties in a hospital setting were the focus of this study, the findings likely apply to other areas of allied health and SLP.

As previously reported across disciplines, the realism of SLEs had a marked effect on the students. ${ }^{11}$ Simulation is, however, restrained in its ability to mimic any "real" environment. Students conveyed a lack of readiness for the "bustle" of the hospital describing "feeling in the way of staff and moving patient beds." One of the limitations of simulation is the inherent lack of "human-ness," even of the high fidelity manikin. ${ }^{40}$ Despite being able to speak, have a pulse, and show chest movements while breathing, the manikin remains a model. As expressed by students, the benefits of "getting to practice on a real patient"has clear advantages to the SLP learner where skills in communication are vital. The use of standardized patients holds merit for SLP training.

Most importantly, the Delayed Placement Feedback focus group data suggest retention of skills and confidence over a threemonth period. Students reported "flash-backs" to the training day both in terms of specific SLP skills and hospital conduct. There is little on the longevity of benefits of SLEs published to date, and this is an important finding for course developers. ${ }^{24}$ In view of the cost and time commitments needed for simulated learning, long-term benefits is a valuable finding.

While SLE may provide the SLP student with technical skills, exposure to a ward environment and the opportunity to practice professional communication skills and clinical reasoning, hospital placements remain vital. This growing field of research suggests that SLEs may allow SLP students to develop entry-level competence while on placement more rapidly.28,29 In time, this may reduce the pressure for external hospital placements if less time in hospital is required to reach competency.

\section{LIMITATIONS \& FUTURE DIRECTIONS}

The questionnaire and focus group questions were not validated. However, all members of the experienced simulation team developed and reviewed the questions for comprehensibility, relevance to the training and clinical significance. Validation and reliability would be beneficial to future projects.

This study looked at students' perceptions before and after one training day. It does not attempt to evaluate behavioural competency or clinical reasoning in students. Further studies looking at field supervisor perceptions and assessments of

(C) The Internet Journal of Allied Health Sciences and Practice, 2015 
competency and clinical reasoning pre- and post- training would add to the SLP evidence-base. This study provides preliminary evidence of retention of skills following simulation training. Further research in this area is needed in SLP and other medical professional groups.

\section{CONCLUSIONS}

The simulated learning environment developed hospital readiness in this cohort of masters speech-language pathology students. Students who attended a one-day simulation-based training day on swallowing difficulties management reported increased confidence, skill-acquisition and a familiarity with the hospital environment. After hospital placements, students attributed their preparedness and willingness to their simulated learning experience, even after a three-month time lag. SLEs have potential to reduce the anxiety of entering the hospital for the first time and give students the opportunity to develop entry-level competency efficiently.

\section{REFERENCES}

1. American Speech-Language-Hearing Association. Scope of practice in speech-language pathology. 2007.

2. American Speech-Language-Hearing Association. Roles of speech-language pathologists in swallowing and feeding disorders: Technical report. 2001.

3. Sheu S, Lin HS, Hwang SL. Perceived stress and physio-psycho-social status of nursing students during their initial period of clinical practice: The effect of coping behaviors. Int J Nurs Stud. 2002;39(2):165-75. [PMID 11755447]

4. McLean M. Sometimes we do get it right! Early clinical contact is a rewarding experience. Educ Health (Abingdon). 2004 Mar;17(1):42-52. [PMID 15203473]

5. Chipchase LS, Buttrum PJ, Dunwoodie R, Hill AE, Mandrusiak A, Moran M. Characteristics of student preparedness for clinical learning: Clinical educator perspectives using the delphi approach. BMC Med Educ. 2012 Nov;12:112. [PMID 23145840]

6. Struthers CW, Perry RP, Menec VH. An examination of the relationship among academic stress, coping, motivation, and performance in college. Research in Higher Education. 2000;41(5):581-92.

7. Eysenck MW. Anxiety and cognitive task performance. Personality and Individual Differences. 1985;6(5):579-86.

8. Clanton J, Gardner A, Cheung M, Mellert L, Evancho-Chapman M, George RL. The relationship between confidence and competence in the development of surgical skills. Journal of Surgical Education. 2014;71(3):405-12.

9. Ebrahimi S, Kojuri J, Ashkani-Esfahani S. Early clinical experience: A way for preparing students for clinical setting. Global Media Journal. 2002;1(2):42-7.

10. Sahu S, Lata I. Simulation in resuscitation teaching and training, an evidence based practice review. J Emerg Trauma Shock. 2010;3(4):378-84. [PMID 21063561]

11. Gordon JA, Oriol NE, Cooper JB. Bringing good teaching cases "to life": A simulator-based medical education service. Acad Med. 2004;79(1):23-7. [PMID 14690993]

12. Como J, Kress M, Lewental M. High fidelity simulation use in an undergraduate nursing program (paper presentation). ASCUE Proceedings. 2009:131-5. https://ascue.org/wp-content/uploads/2014/11/2009-final.pdf

13. Ward EC, Baker SC, Wall LR, Duggan BL, Hancock KL, Bassett LV, Hyde TJ. Using simulation in tracheostomy management: Can human mannequin-based simulation provide a feasible and clinically acceptable method for training tracheostomy management skills for speech-language pathologists? Am J Speech Lang Pathol. 2014 Aug;23(3):421-36. [PMID 24686737]

14. Hill AE, Davidson BJ, Theodoros DG. Speech-language pathology students' perceptions of a standardised patient clinic. $J$ Allied Health. 2013;42(2):84-91. [PMID 23752235]

15. Butina M, Brooks D, Dominguez PJ, Mahon GM. Utilization of virtual learning environments in the allied health professions. J Allied Health. 2013 Spring;42(1):e7-10. [PMID 23471291]

16. McLaughlin SA, Doezema D, Sklar DP. Human simulation in emergency medicine training: A model curriculum. Emergency Medicine. 2002 Nov;9(11):1310-8. [PMID 12414487]

17. Shrader S, Kern D, Zoller J, Blue A. Interprofessional teamwork skills as predictors of clinical outcomes in a simulated healthcare setting. J Allied Health. 2013;42(1):e1-6. [PMID 23471287]

18. Deutsch ES. High-fidelity patient simulation mannequins to facilitate aerodigestive endoscopy training. Arch Otolaryngology Head and Neck Surg. 2008;134(6):625-9. [PMID 185597390]

19. Kennedy CC, Maldonado F, Cook D. Simulation-based bronchoscopy training: systematic review and meta-analysis. Chest. 2013 Jul;144(1):183-92. [PMID 23370487]

20. Shoemaker MJ, Beasley J, Cooper M, Perkins R, Smith J, Swank C. A method for providing high-volume interprofessional simulation encounters in physical and occupational therapy education programs. J Allied Health. 2011;40(1):e15-21. [PMID 21399842] 
21. Shapiro MJ, Morey JC, Small SD, Langford V, Kaylor CJ, Jagminas L, Suner S, Salisbury ML, Simon R, Jay GD. Simulation based teamwork training for emergency department staff: Does it improve clinical team performance when added to an existing didactic teamwork curriculum? Qual Saf Health Care. 2004;13(6):417-21. [PMID 15576702]

22. Herge EA, Lorch A, Deangelis T, Vause-Earland T, Mollo K, Zapletal A. The standardized patient encounter: A dynamic educational approach to enhance students' clinical heathcare skills. J Allied Health. 2013;42(4):229-35. [PMID 24326920]

23. Benadom EM, Potter NL. The use of simulation in training graduate students to perform transnasal endoscopy. Dysphagia. 2011;26(4):352-60. [PMID 21127910]

24. Rodgers D. High-fidelity patient simulation: A descriptive white paper report. Healthcare Simulation Strategies. 2007. http://t.sim-strategies.com/downloads/Simulation\%20White\%20Paper2.pdf

25. Issenberg SB, Gordon MS, Gordon DL, Safford RE, Hart IR. Simulation and new learning technologies. Med Teach. 2001;23(1):16-23. [PMID 11260734]

26. Shaffer D, Dawson S, Meglan D, Ferrell M, Norbash A. Design principles for the use of simulation as an aid in interventional cardiology training. Minim Invasive Ther Allied Technol. 2001;10(2):75-82. [PMID 16753994]

27. Watson K, Wright A, Morris N, McMeeken J, Rivett D, Blackstock F, Jones A, Haines T, O'Connor V, Watson G, Peterson R, Jull G. Can simulation replace part or clinical time? Two parellel randomised controlled trials. Med Educ. 2012;46(7):65767. [PMID 22646319]

28. Woolliscroft JO, Calhoun JG, Tenhaken JD, Judge RD. Harvey: The impact of a cardiovascular teaching simulator on student skill acquisition. Med Teach. 1987;9(1):53-7. [PMID 3669990]

29. Wayne DB, Butter J, Siddal VJ, Fudala MJ, Wade LD, Feinglass J, McGaghie WC. Mastery learning of advanced cardiac life support skills by internal medicine residents using simulation technology and deliberate practice. J Gen Intern Med. 2006;21(3):251-61. [PMID 16637824]

30. Van Heukelom JN, Begaz T, Treat R. Comparison of postsimulation debriefing versus in-simulation debriefing in medical simulation. Simul Healthc. 2010 Apr;5(2):91-7. [PMID 20661088]

31. McAllister S, Lincoln M, Ferguson A, McAllister L. COMPASS TM: Competency assessment in speech pathology. 2011.

32. Rose M, Best D. Transforming practice through clinical education, professional supervision and mentoring. London, UK: Elsevier Ltd; 2005.

33. McAllister S, Lincoln M. Methods in speech language pathology series. Clinical education in speech language pathology. London, UK: Whurr Publications Ltd; 2004.

34. Kitzinger J. Qualitative research: Introducing focus groups. BMJ. 1995;311(7000):299-302. [PMID 7633241]

35. Power H, Single H. Methodology matters: Focus groups. International Journal of Quality in Health Care. 1996;8(5):499-504.

36. Krueger R. Focus groups. A practical guide for applied research (2nd ed). Thousand Oaks: Sage Publications Inc; 1994.

37. Braun V, Clarke V. Using thematic analysis in psychology. Qualitative Research in Psychology. 2006;3(2):77-101.

38. Morgan PJ, Cleave-Hogg D, Desousa S, Lam-McCullough J. Applying theory to practice in undergraduate education using high fidelity simulation. Med Teach. 2006;28(1):e10-5. [PMID 16627314]

39. MacBean N, Theodoros D, Davidson B, Hill AE. Simulated learning environments in speech-language pathology: An australian response. Int J Speech Lang Pathol. 2013;15(3):345-57. [PMID 23586581]

40. Greenberg R, Loyd G, Wesley G. Integrated simulation experiences to enhance clinical education (abstract). Medical Education. 2002;36(1):1109-10. [PMID 12406301]

\section{Acknowledgements:}

Thank you to the staff at The University of Auckland Simulation Centre for Patient Safety, Tamaki Campus for their expertise: Jane Torrie, Abbey Gundesen and Brenda Knowles. The authors would like to specifically acknowledge the support of Jane Torrie in both training day planning and manuscript preparation. Thank you to Bianca Gordon, Emma Necus and Malcolm Borrie for their contribution to the planning and facilitation of the training day. 